\title{
A segurança jurídica e a efetividade jurisdicional na conciliação: uma análise crítica-reflexiva sobre a concreção do Instituto nos Moldes do Novo CPC
}

\author{
Legal security and jurisdictional effectiveness in conciliation: \\ a critical-reflective analysis on the concretion of the institute in \\ the Molds of the New CPC
}

\author{
Fernanda Morato da Silva Pereira ${ }^{1}$, Heloísa Chubaci Bezerra de Menezes $^{2}$, Lucas de Souza Lehfeld ${ }^{2}$ \\ ${ }^{1}$ Programa de Pós-graduação em Direito Processual do Trabalho, Centro Universitário da Fundação \\ Educacional de Barretos (UNIFEB) - Barretos (SP), Brasil. \\ ${ }^{2}$ UNIFEB - Barretos (SP), Brasil.
}

\section{Resumo}

O artigo se propôs a uma análise crítica-reflexiva da concreção do instituto da conciliação no novo Código de Processo Civil, à luz do processo constitucionalizado que busca um processo justo e de resultados satisfatórios, através da garantia da segurança jurídica e efetividade jurisdicional. Questionou-se a real implementação do instituto no dia a dia forense e o seu objetivo primordial, como medida alternativa de solução de conflito. A problemática levantada destinou-se a cuidar da efetividade da segurança jurídica quando há minimização (ausência) do formalismo processual que está presente, em tese, no procedimento da conciliação. Foi possível verificar que essa falta de formalismo contradita o que estabelece o código, pois ele obriga a participação das partes da conciliação, inobstante a impossibilidade de autocomposição. Pautou-se, portanto, em analisar os pontos desfavoráveis à sua eficácia, constatando que sua obrigatoriedade, como ato inaugural, burocratiza o processo, caminhando na contramão dos anseios do novo código, afastando o jurisdicionado da jurisdição, denegando o acesso à justiça em sua plenitude, à segurança jurídica e ao provimento jurisdicional de qualidade. Identificou-se, ainda, que quebra da autonomia pode oportunizar manobras processuais protelatórias, aumentando a lentidão e descumprindo a celeridade processual, uma promessa também codificada. Para tanto, foi necessário o uso da metodologia no campo da pesquisa bibliográfica, nas áreas dedutiva e indutiva. A primeira, por meio do estudo do Direito Processual Civil sob a ótica do Direito Constitucional. A pesquisa partiu da legislação, alcançando conceitos e estudos doutrinários sobre o tema. A segunda, perfazendo o estudo da realidade, especialmente no tocante à essência da mentalidade do povo brasileiro e do que ele entende ser o real exercício do direito e da justiça. Conclui-se que o instituto da conciliação, previsto como meio alternativo jurisdicional de solução de conflito, inobstante ter sido acertada sua codificação, ainda depende de aspectos sociais para sua concreção. Isso porque, atualmente, vem sendo aplicado como instrumento de extermínio de demandas, sem trabalhar de fato o conflito em si. Não busca, portanto, a efetiva e adequada solução do conflito, pois deixa de considerar as peculiaridades e necessidades das partes, fazendo-as obrigatoriamente cumprir o rito processual sem dar a chance de efetivamente as partes alcançarem segurança jurídica e uma tutela jurisdicional justa e com resultado satisfatório. Assim, apesar da necessidade de ser contextualizada no código, a justiça conciliatória precisa passar por um procedimento de conscientização da sua real importância, para que os diretamente envolvidos (e também a sociedade) passem a acreditar no instituto, ao passo que o próprio judiciário esteja preparado para receber e tratar o conflito em si, para que, dessa forma, seja possível alcançar a concreção do instituto conforme ele foi inicialmente proposto pelo legislador.

Palavras-chave: conciliação; concreção; processo constitucionalizado.

Autor para correspondência: Fernanda Morato - Av. Professor Roberto Frade Monte, 389 - Aeroporto - CEP: 14283-078 - Barretos (SP), Brasil-E-mail: fernandamorato@live.com

Recebido em: 30 de maio de 2017

Aceito para publicação em: 01 setembro de 2017 


\begin{abstract}
The article proposed a critical-reflexive analysis of the concretion of the conciliation institute in the new Code of Civil Procedure, in light of the constitutional process that seeks a fair process and satisfactory results through the guarantee of legal certainty and jurisdictional effectiveness. It was questioned the actual implementation of the institute on a day-to-day forensic basis and its primary objective as an alternative measure of conflict resolution. The problem raised was intended to take care of the effectiveness of legal certainty when there is minimization (absence) of procedural formalism that is present, in theory, in the conciliation procedure. It was possible to verify that this lack of formalism contradicts what the code establishes, since it forces the participation of the conciliation parts, notwithstanding the impossibility of self-composition. Therefore, it was decided to analyze the points unfavorable to its effectiveness, noting that its obligation, as an inaugural act, bureaucratises the process, moving against the aspirations of the new code, removing the jurisdictional from the jurisdiction, denying access to justice in its completeness, legal certainty and the provision of judicial quality. It was also identified that the breakdown of autonomy may favor delayed procedural maneuvers, increasing the slowness and avoiding procedural celerity, a promise also codified. For that, it was necessary to use the methodology in the field of bibliographic research, in the areas of deductive and inductive. The first one is through the study of Civil Procedural Law from the point of view of Constitutional Law. The research started from the legislation, reaching doctrinal concepts and studies on the subject. The second is the study of reality, especially regarding to the essence of the mentality of the Brazilian people and what it considers to be the real exercise of law and justice. It was concluded that the conciliation institute, envisaged as an alternative jurisdictional means of conflict resolution, notwithstanding that its codification has been agreed, still depends on social aspects for its concretion. This because today it has been applied as an instrument of extermination of demands, without actually working the conflict itself. Therefore, it does not seek the effective and proper solution of the conflict, since it fails to consider the peculiarities and needs of the parties, obliging them to comply with the procedural rite without giving the parts the opportunity to achieve legal certainty and a fair satisfactory judicial result. Thus, in spite of the need to be contextualized in the code, conciliatory justice must go through a procedure of awareness of its real importance, so those directly involved (and also society) come to believe in the institute, while the judiciary itself is prepared to receive and treat the conflict itself, to be possible to achieve the realization of the institute as it was initially proposed by the legislator.
\end{abstract}

Keywords: conciliation; concretion; constitutional process.

\section{Introdução}

A ciência humana tem como propósito regular as relações interpessoais, melhorando a convivência entre os indivíduos e promovendo a paz social. O direito, por sua vez, assume papel indispensável nas transformações sociais, ou seja, está em constante mudança para atender à evolução da sociedade.

Sem adentrar aos aspectos peculiares, mas historicamente falando, o papel do Estado Liberal consistia numa atuação normativa rígida e com estrito respeito à persecução processual. Garantia a segurança jurídica no momento em que afastava o direito material, dando lugar ao direito processual, ou seja, a segurança jurídica era promovida e garantida por meio da lei e do formalismo acentuado. A aplicação da lei sobrepunha-se, inclusive, aos ideais de justiça e aos valores morais. Sendo a lei consequência da vontade do povo, o processo era pautado exclusivamente na estrita legalidade e o direito material tratado de forma isolada.
O Estado de Direito originou a submissão da sociedade ao poder do Estado firmando a dependência do povo ao poder estatal. Essa escravidão chegou ao ponto de torná-los incapazes de pôr fim aos próprios conflitos. Isso porque o Estado atuava (e ainda atua) como principal figura na resolução de conflitos, inclusive por não promover - na maioria das vezes - de forma plena as garantias constitucionais, tema que demanda aprofundamento distinto do ora proposto. Uma vez que o Estado é o centro de solução dos conflitos, o povo deposita nele confiança e responsabilidade na solução dos conflitos, logo, o sistema é transformado em algo moroso e ineficiente, pelo volumoso número de processos propostos diariamente no País.

A morosidade não preocupa apenas o Judiciário, mas todas as esferas do Poder, ganhando maior ênfase na última década. Entretanto, maior que a preocupação com a morosidade deve ser a preocupação com o descumprimento dos princípios da segurança jurídica e efetividade 
processual, desaguando no princípio do acesso à justiça. A importância deve ser igualmente distribuída, pois a solução da crise do Judiciário está ancorada nos institutos alternativos de solução de conflitos, institutos estes que na prática nem sempre prestigia os princípios ora mencionados. Muitas vezes a prática contradita a teoria, sendo impossível mensurar se, em todos os processos solucionados através dos meios alternativos, a segurança jurídica e a efetividade jurisdicional foram de fato alcançadas, inobstante ter sido respeitado o princípio da celeridade processual.

A jurisdição brasileira convive com a crise, e é fato que a morosidade deriva do acúmulo de processos, pois o Poder Judiciário é chamado a resolver todos os conflitos, tanto os passíveis de solução amigável, quanto os que poderiam ser evitados. Mas, a morosidade não é o único motivo. Somada ao sistema capitalista, à falta de política pública direcionada à resolução de conflitos, ao ativismo judicial e à judicialização, agrava a situação e distancia o problema da sua solução. Até porque o Poder Público passou de mero detentor do poder técnico para detentor de poder político e, estando a sociedade consciente e com maior nível de informação, a busca pela proteção e concretização de seus direitos aumentou a movimentação estatal.

Sobre a morosidade no judiciário, Juliano da Costa Stumpf (2008, p. 12) elucida que:

As causas internas da morosidade são aquelas cujo seu enfrentamento está ao alcance do próprio Judiciário, por iniciativa direta, ainda que influenciadas sejam de modo indireto por fatores outros. Já as causas externas estão fora da ação direta e exclusiva do Poder Judiciário, ou seja, dependem da ação e do exercício de competências atribuídas aos demais Poderes ou, pelo menos, de uma mudança cultural no âmbito da própria comunidade.

É clarividente que a cultura demandista enraizada no País é umas das principais, senão a principal, causa da morosidade. Sendo a decisão judicial único método para eliminar conflitos, esta não se mostra mais útil à população, porque em sua maioria é proferida tardiamente. A propositura de demandas desenfreadas ao lado de um sistema processual falho impede que o Poder Judiciário responda em tempo útil às demandas levadas até ele, distanciando, evidente e inequivocamente, o jurisdicionado da jurisdição, por consequência, negando o acesso à justiça.
No Brasil, a vontade de litigar é inerente às pessoas, fato comprovado pelo abarrotamento de infindáveis processos, o que leva ao descumprimento do princípio da razoável duração do processo, previsto no inciso LXXVIII, art. $1^{\circ}$ da Constituição Federal, impedindo o cumprimento do acesso à justiça em sua plenitude, também estabelecido na Constituição Federal, art. $5^{\circ}$, inciso XXXV (BRASIL, 1988).

O cidadão que movimenta a máquina estatal, na maioria das vezes, está mais interessado em amenizar a sensação de uma possível derrota do que realmente resolver o conflito, isso porque o jurisdicionado busca a última instância para conseguir a sentença desejada, por consequência, tumultua o processo, tornando-o moroso. Tudo isso para suprir o sentimento de justiça.

Segundo Ricardo Pereira Junior (apud SILVA, 2014, p. 29):

A cultura da sentença e do recurso que se tem alimentado no Brasil, tornou o direito um domínio de especialistas, dificultando a prática do exercício de direito pelos próprios cidadãos que, frente à amplitude da técnica legal do judiciário, viram sua cidadania apequenada dentro de uma lógica formal que não se atenta às necessidades do usuário, apenas organiza passos procedimentais técnicos que não promovem convivência e pacificação social.

As partes, o advogado e o juiz ficam adstritos às previsões legais e nem sempre o Judiciário consegue alcançar a verdade real dos fatos, assim, para garantir a segurança jurídica, o juiz acaba se valendo de uma verdade fictícia, que nem sempre corresponde à realidade dos desejos dos envolvidos. Isso significa dizer que a busca pela melhor verdade de cada parte nem sempre é aprofundada.

Neste sentido, o novo CPC trouxe importante inovação, pois colocou as partes como protagonistas ao prever a responsabilidade de cooperação entre elas. Objetivando que, em tempo hábil e razoável, a sentença seja proferida de forma justa e efetiva. Essa previsão está determinada no art. $6^{\circ}$ do novo CPC, modernizando o ordenamento jurídico, quando, de certa forma, deixa em segundo plano o extremo formalismo processual para incluir a participação das partes na resolução do caso, buscando assim alcançar e efetivar o desejo dos envolvidos.

Além da previsão do princípio da cooperação, os meios consensuais de conflitos foram amplamente 
previstos no novo código, demonstrando claro incentivo à resolução de conflitos pelas próprias partes envolvidas e, por consequência, buscando amenizar a morosidade. Com isso, a justiça conciliatória passa a ser vista como mecanismo adequado para diminuir o abarrotamento de processos, a lentidão processual e oferecer um acesso à justiça de qualidade ao cidadão. Ou seja, a resolução de conflitos através da participação popular no exercício dos direitos e da administração da justiça (BENEDITO, 2017).

Quando se fala em justiça, importante destacar Hans Kelsen, pois para ele "[...] felicidade social é o anseio do homem por felicidade, contudo, não de forma individual, mas de modo a contentar todos [...]" (NUNES JUNIOR, 2015). Para ele, o significado de justiça passou por transformações ao longo do tempo, o sentido original e subjetivo da palavra era o sentimento que cada pessoa compreende para si, transfigurando-se para a satisfação das necessidades coletivas e não apenas as individuais (NUNES JUNIOR, 2015).

A jurisdição brasileira enfrenta há tempos o problema da morosidade, seja por conta da propositura desenfreada de demandas, de recursos intermináveis ou da falha do sistema processual. Apesar das inúmeras tentativas de solucionar este fato, é determinante a conscientização das partes e o envolvimento verdadeiro do judiciário com o caso concreto. Isso porque toda a preocupação está direcionada na solução do conflito de forma superficial, esquecendo-se da origem que envolveu as partes conflitantes. Não se pode admitir que a segurança jurídica e a efetividade da tutela jurisdicional sejam prejudicadas, para que os meios alternativos de solução de conflitos sejam concretizados, visando acima de tudo solucionar a morosidade do judiciário.

A busca da solução do conflito deve ser sempre priorizada, quer seja por meio da prolação de uma sentença ou por meios alternativos, desde que promova segurança jurídica e efetividade da tutela, concretizando o acesso à justiça. É bem verdade que nem sempre a sentença é sinônimo de vitória, pois muitas vezes seu cumprimento é frustrado. Por isso, é preciso que os meios alternativos sejam oportunizados e não impostos, que sejam conduzidos com responsabilidade e técnica, buscando de forma justa e efetiva a solução do conflito e não exterminar demandas.

\section{Material e Métodos}

A pesquisa bibliográfica foi feita nas áreas do Direito Constitucional e Direito Processual Civil, de modo a satisfazer análise de dados dedutiva - a partir da interpretação legislativa, conceitos doutrinários, teorias e jurisprudências atuais - além da indutiva, perfazendo o estudo da realidade fática, passando pela análise multidisciplinar que envolve estudos das ciências humanas.

O estudo da Resolução n. 125 do Conselho Nacional de Justiça (BRASIL, 2010) foi indispensável para a perfeita compreensão da produção científica em questão.

A análise jurisprudencial, especialmente vinculada ao entendimento do Supremo Tribunal Federal, sobre acesso à justiça, efetividade jurisdicional e segurança jurídica, também foi utilizada como ferramenta para que as finalidades do estudo sejam alcançadas.

\section{Resultados e Discussão}

A morosidade do sistema processual colocou os meios alternativos no centro da solução dos conflitos, tornando-os protagonistas no Judiciário. Instituídos inicialmente pela Resolução n. 125 do Conselho Nacional de Justiça e, hoje, amplamente descritos no texto do novo Código de Processo Civil, assumem dois importantes papéis, promover a pacificação social e aniquilar demandas, contribuindo com a redução do número de processos e para a diminuição da morosidade. Tal previsão propõe o restabelecimento do sistema processual vigente, garantindo o acesso à justiça - com a segurança jurídica e efetividade jurisdicional -, sem mitigar, sobretudo, o princípio da celeridade processual, à luz de um processo justo e constitucionalizado.

Contudo, a proposta do legislador pode não estar sendo concretizada na prática. Talvez esteja na contramão da proposta inicial ao ser instituto de forma obrigatória, submetendo o jurisdicionado ao exercício forçado da jurisdição participativa, o que é prejudicial, principalmente, pela falta de preparo e conhecimento da população acerca do funcionalismo processual, do princípio do acesso à justiça e dos meios consensuais como instrumento de paz social.

$\mathrm{O}$ acesso à justiça é compreendido pelo povo como o simples acesso formal aos órgãos do Poder Judiciário e não como garantia plena de um acesso de qualidade, que dê ao jurisdicionado a segurança jurídica devida na resolução de seu conflito. Essa 
confusão entre acesso à justiça e resultado do processo ocorre porque a mentalidade do cidadão está ligada à sua satisfação com o resultado final do processo e não com o acesso (de fato) ao Poder Judiciário, no qual é oportunizada a relação processual para resolver o bem da vida (SILVA, 2014, p. 15).

Nesse sentido, vale dizer que a Constituição Federal não prevê a prolação de uma sentença como requisito obrigatório para concreção do princípio do acesso à justiça. Mas, a cultura brasileira interpreta equivocadamente o princípio e o vincula à decisão judicial, porque acredita que só através dela é possível conseguir aquilo que é justo. Porém, a inafastabilidade da jurisdição compreende a prevenção e reparação de direitos; a realização de soluções negociadas e o fomento da mobilização da sociedade, com a participação ativa dos procedimentos (SILVA, 2014, p. 16).

$\mathrm{O}$ acesso à justiça deve ser instrumento de aproximação daquele que busca o "provimento" jurisdicional ao resultado satisfatório do conflito e não a satisfação do problema em si, até porque isso é impossível, considerando que duas partes conflitantes têm desejos e expectativas distintas. Boaventura de Sousa Santos estabelece uma distinção entre acesso à justiça, a administração da justiça e a litigiosidade social, equacionando as relações entre processo civil e justiça social e entre igualdade jurídico-formal e desigualdade socioeconômica (SANTOS, 1999, p. 167).

Nesta ocasião, a valoração negativa que se dá ao conflito precisa ser afastada, porque, desde que existe o homem, as relações interpessoais são seu alimento de sobrevivência, logo, a percepção que cada pessoa tem sobre o mesmo assunto desencadeia conflitos, que são inerentes aos seres humanos. É

[...] uma situação de concorrência, onde as partes estão conscientes da incompatibilidade de futuras posições potenciais, e na qual uma delas defende ocupar uma posição incompatível com os desejos da outra. (SILVA, 2014, p. 20).

Entender o conflito é essencial, porque esse entendimento facilitará o diálogo, viabilizando uma aproximação entre as partes, para que elas possam de fato buscar uma solução satisfatória para o problema [...] (DEMARCHI, 2007, p. 51).

Pacificação social não significa exterminar conflitos, ela é alcançada quando ao conflito é dada uma solução adequada, através da composição das partes, favorecendo o diálogo e a compreensão do problema. A cooperação das partes é fator determinante, mas para que isso se materialize é indispensável que as partes estejam conscientes da importância da cooperação, que atuará de modo decisivo, exercendo e fortalecendo o exercício da democracia. Para solucionar conflitos (e não demandas), o ideal é que a participação das partes seja incluída como fator decisório, preservando o relacionamento interpessoal e promovendo a justiça coexistencial.

É inquestionável que o acesso à justiça desmedido e inconsequente é causado pela mentalidade dos cidadãos, que, em busca do sentimento de justiça, litigam desenfreadamente, abarrotando e tornando lento o judiciário brasileiro, ferindo a efetividade e a celeridade processual, suprimindo o devido processo legal, contribuindo para que o sistema processual seja inadequado e inconclusivo. Para Flávia de Almeida Montingelli Zanferdini (2014, p. 2-3 apud SILVA, 2014, p. 36), “[...] se está a justiça em crise, por consequência o processo como instrumento de solução de litígio também está $[\ldots . . . "$.

No Brasil, há acesso à justiça, no entanto não é possível garantir a segurança jurídica e a efetividade jurisdicional, em especial, quando se trata da conciliação obrigatória como meio alternativo de solução de conflito. Isso significa dizer que o acesso à justiça não está sendo cumprido em sua plenitude, uma vez que cumpre meramente o exercício do direito de ação do jurisdicionado ao movimentar o judiciário, mas, a resolução do conflito não é realizada de forma justa e constitucionalizada.

Consciente da crise do judiciário, em especial, da morosidade, o novo CPC tratou de inserir em seu texto mudanças que visam proporcionar um processo mais justo e de resultados satisfatórios, tornando mais simples as questões corriqueiras do dia a dia das pessoas. Ao apoiar a arbitragem e o incentivo aos meios consensuais, coloca a conciliação como principal ferramenta, com nítido objetivo de transformar a mentalidade do povo brasileiro para que, talvez, consiga amenizar a lentidão. É gritante a aposta do novo CPC nos meios consensuais de resolução de conflito, citando em seu texto base as palavras mediação e conciliação ao menos 44 vezes (GAJARDONI, 2015), além de disciplinar no artigo $3^{\circ}$ o dever do Estado em promover a solução consensual de conflitos.

Foi incorporada no texto legal a previsão aprovada na resolução 125 do CNJ, acolhendo, por 
consequência, uma teoria de Kazuo Watanabe que trata do "acesso à ordem jurídica justa" (MELO, $2015)^{1}$ e, nesse contexto, traz para o processo os meios consensuais de solução de conflitos, ressaltando que não se fala mais em meios alternativos, mas meios jurisdicionais, até porque não há mais sentença de mérito típica e atípica, pois a homologação será sempre uma sentença típica, já que é um mecanismo jurisdicional.

A proposta (e expectativa) do legislador é de que o acordo formulado a partir da participação direta das partes, sem a interferência do formalismo processual, resulte no seu integral cumprimento, porque, em regra, a confiança mútua foi restabelecida, especialmente, por não ter parte vencida, mas sim composição amigável, baseada no bom senso. Segundo Maria Lúcia Ribeiro de Castro Pizzotti Mendes (2014 apud SILVA, 2014, p. 17):

Este é um dos principais fundamentos das vias conciliativas, pois busca racionalizar a distribuição da justiça a partir da solução de certas controvérsias por meio autocompositivos, o que dispensa, muitas vezes a adequação técnica processual e, traz ainda, como consequência a desobstrução dos tribunais melhorando o desempenho e a funcionalidade da justiça.

Inobstante os instrumentos alternativos sejam complementares ao sistema jurisdicional, devendo ser levados ao conhecimento e alcance de todos, eles ainda não conseguem oferecer resposta de fácil compreensão e em tempo hábil. Motivo pela qual a discussão aqui foi proposta.

A função da justiça conciliatória consiste:

[...] na possibilidade de as partes resolverem seus problemas, liberdade para a discussão das questões deduzidas no processo e também de outras que porventura não sejam objeto do pedido, busca

\footnotetext{
${ }^{1}$ No conceito de acesso à Justiça, ou acesso à ordem jurídica justa, o Prof. Kazuo Watanabe, inseriu o que ele chama de dados elementares: "(1) o direito à informação e perfeito conhecimento do direito substancial e à organização de pesquisa permanente a cargo de especialistas e orientada à aferição constante da adequação entre a ordem jurídica e a realidade socioeconômica do País; (2) direito de acesso à Justiça adequadamente organizada e formada por juízes inseridos na realidade social e comprometidos com o objetivo de realização da ordem jurídica justa; (3) direito à preordenação dos instrumentos processuais capazes de promover a efetiva tutela de direitos; (4) direito à remoção de todos os obstáculos que se anteponham ao acesso efetivo à Justiça com tais características". "Acesso à Justiça e sociedade moderna” (MELO, 2015).
}

dos reais interesses dos envolvidos, e não no assoberbamento do Poder Judiciário, que representa a garantia do Estado de que conflitos serão resolvidos (DEMARCHI, 2007, p. 57).

É indiscutível que os métodos conciliatórios fortalecem o Judiciário, promovendo o acesso à justiça de qualidade, pois visam reorganizar o sistema judicial e possibilitar que o Estado ofereça outros meios de se fazer justiça, que não por meio da imposição de cumprimento de uma sentença, satisfazendo apenas uma das partes.

A conciliação como meio alternativo jurisdicional de solução de conflito, tem previsão obrigatória, conforme quis o legislador no novo CPC em seu art. $3^{\circ}$. Ela se destina à resolução do conflito natural de uma relação circunstancial. $\mathrm{O}$ vínculo entre as partes é inerente ao problema enfrentado e não à relação, por isso, através de sugestões de acordo dadas pelo conciliador, se pretende o fim do conflito. Demanda um procedimento célere, por conta da natureza e complexidade da causa.

$\mathrm{O}$ cidadão jurisdicionado não considera a conciliação efetiva, pois, apesar de colocar as partes diretamente para negociar, promovendo a democracia participativa, elas são inaptas para exercer o pleno domínio do processo, porque desconhecem o ordenamento jurídico e nem sempre procuram advogado para receber a orientação e acompanhamento devidos.

Por ser um método mais invasivo, a conciliação permite que o conciliador atue de forma incisiva e focada no acordo, com intuito de pôr fim ao problema que ocasionou a demanda, sugerindo acordos e pontuando soluções. Por isso, se aplica a casos em que não há uma relação continuada entre os envolvidos, porque cuida de acontecimentos que originaram determinada demanda e não com o futuro daquela relação desequilibrada, ou seja, a técnica da conciliação "trata de relacionamento meramente circunstancial” (DEMARCHI, 2007, p. 54).

Acertadamente a proposta do legislador foi adequada, porque a principal busca processual é a pacificação social, logo, promovê-la por meio de instrumentos autocompositivos constrói alicerce seguro para a solução do conflito. Inobstante a proposta da conciliação como ato inaugural do processo seja ideal e bem fundamentada, alguns problemas podem frustrar o ora pretendido. Porém, a mentalidade da população estritamente litigante, alimentada por uma cultura demandista 
somada à limitação em compreender o princípio constitucional do acesso à justiça, bem como a falta de gestão da justiça são fatores que, inicialmente, podem contribuir negativamente para a efetividade e eficácia do instituto.

Fernando da Fonseca Gajardoni (2015) elenca os possíveis fatores prejudiciais:

a) quebra-se aquilo que de mais caro há nos métodos consensuais de solução de conflito, a autonomia da vontade, lançada pelo próprio legislador como princípio da mediação (art. 166 CPC/2015);

b) burocratiza-se a mediação/conciliação, obrigando todas as partes, mesmo não querendo, a se submeter a ela, simplesmente porque uma delas deseja;

c) dá azo a manobras processuais protelatórias, com um dos demandados aceitando a audiência, apenas, para ganhar mais alguns meses de tramitação processual, sem possiblidade de intervenção judicial para obstar a manobra;

d) torna maior o custo do processo, pois além do pagamento pelos serviços do mediador/conciliador, o demandado domiciliado em outra localidade, praticamente em todas as ações, deverá se deslocar para a audiência de mediação/conciliação no foro da propositura. E tudo isso temperado pela cominação de que o não comparecimento injustificado ao ato será considerado ato atentatório à dignidade da justiça, sancionando-se o ausente com multa de até dois por cento da vantagem econômica pretendida ou do valor da causa, revertida em favor da União ou do Estado (art. 334, § 8 , $\mathrm{CPC} / 2015)$.

Em resumo, as partes não são citadas para apresentarem defesa, mas para fazer acordo. Ao receber a Inicial, o Juiz designará audiência de conciliação (ou mediação), a ser conduzida por profissional qualificado, sendo vedado dispensar a audiência, mesmo quando vislumbrar a inexistência de possibilidade de autocomposição. Portanto, a audiência de conciliação é obrigatória. A dispensa da audiência só ocorrerá quando ambas as partes se manifestarem acerca do desinteresse na audiência conciliatória, contudo, se apenas uma parte requerer, ela será realizada. A ausência injustificada na audiência configura ato atentatório à dignidade da justiça com aplicação de multa em $2 \%$ do valor da vantagem econômica ou da causa, revertidos para a União ou Estado, consoante art. 331, §8 $8^{\circ} \mathrm{NCPC}$.

A obrigatoriedade da audiência conciliatória, além de burocratizar o processo, tornando-o formal, contrariando a intenção inicial do legislador, que é torná-lo informal e acessível ao povo, pode ensejar a prática de manobras protelatórias por aquele que não tem interesse em solucionar o conflito. $\mathrm{O}$ ato protelatório pode ocorrer por motivos diversos, um deles pode estar cravado na descrença na autocomposição como meio de "fazer justiça". Ganhar tempo pode ser outro motivo prejudicial, afetando a eficácia do instituto e o princípio da celeridade processual, outra promessa do novo CPC. A eficácia será prejudicada pelo simples fato de a obrigatoriedade contradizer norma prevista pelo próprio texto legal, quando disciplina a autonomia da vontade das partes.

Ao determinar a audiência inaugural como obrigatória, o judiciário confessa a falência do sistema, pois a impõe como único caminho para exercício do direito e acesso à justiça, afastando o jurisdicionado do devido processo legal e, pior, fazendo-o desacreditar no sistema processual ao atestar a morosidade crônica do judiciário. Além de exigir uma mudança cultural do cidadão brasileiro, o judiciário, forçosamente, exige a mudança comportamental da comunidade jurídica, incutindo a ideia de que o meio consensual é sempre melhor do que uma sentença. Essa interpretação é equivocada, assim como a ideia contrária, pois o melhor é aplicar as ferramentas processuais de forma adequada, considerando cada caso isoladamente, com interesse precípuo em resolver o conflito e não a demanda.

Vale transcrever o pensamento de Dínio de Santis Garcia (1996, p. 154 apud STUMPF, 2008, p. 12), qual seja "[...] a melhor justiça seria a que decidisse a causa de imediato [...]". Seguindo o pensamento, Barbosa Moreira (2000, p. 8 apud STUMPF, 2008, p. 12) entende que "[...] uma Justiça lenta demais é de certo uma justiça má, daí não se negue que uma Justiça muito rápida seja necessariamente uma Justiça boa [...]”. É necessário e indispensável para a eficácia dos meios consensuais, que nas audiências seja construído conjuntamente o alicerce para a solução razoável do conflito, que não seja nem a melhor e nem a pior possível, mas algo positivo para os envolvidos.

A justiça conciliatória só efetivará o instituto quando contribuir de fato para que as partes encontrem o equilíbrio existente na relação antes da origem do conflito, identificando o ponto que desencadeou a insatisfação e desorganizou a relação. Neste momento, será possível que a negociação 
tenha como instrumento o meio conciliatório, desde que, evidentemente, sua estrutura seja adequada.

Inobstante o amplo incentivo no novo códex, a concreção do meio consensual da conciliação demanda aspectos não previstos no código, como a estruturação adequada do judiciário, facultatividade e vontade das partes, gratuidade, formalismo equilibrado, ampla informação sobre o instituto e sua importância no ordenamento jurídico e na sociedade e, não menos importante, a vocação dos conciliadores. É preciso mais que a preparação destes profissionais, é necessário que tenham vocação e dedicação para dirimir conflitos.

Sabendo que a segurança jurídica é o princípio equalizador do formalismo e da flexibilidade e que busca, sobretudo, a efetividade processual, é possível afirmar que há segurança jurídica onde não há formalismo? Sabendo que nas audiências conciliatórias o formalismo é dispensado, é possível garantir a segurança jurídica ao jurisdicionado? É bem verdade que a evolução do direito estigmatizou a segurança jurídica, pois evidente a minimização do formalismo e do legalismo, que deu lugar a um processo ágil, através do equilíbrio de regras e princípios. Atualmente, não se prestigiam apenas as formas processuais, mas, sobretudo, a aproximação do direito material do processual.

Para responder às perguntas, cabe entender a necessidade de afastar do processo o formalismo negativo, com cautela, para que o processo seja conduzido totalmente informal, pois é indispensável valorar as "formas" para efetivar o direito material. O formalismo negativo são "as regras do jogo" e consiste na organização do processo, define limites e garantias, oferece previsibilidade e evita desordem. Formalismo valorativo, por sua vez, define a atuação das partes, oferece equilíbrio, favorece o contraditório, regula a atuação do juiz, favorece a igualdade e constitui método de controle da atividade judicial, garantindo segurança jurídica e efetividade da tutela jurisdicional (CAMBI; BUENO, 2014).

A segurança jurídica protege a confiança através da previsibilidade da Lei e de seus efeitos, se externa através da estabilidade, calculabilidade, confiança e previsibilidade. Uma vez que a segurança jurídica é fruto do formalismo e do legalismo, é possível garanti-la nos acordos firmados nas audiências conciliatórias, tendo em vista a quase inexistência de formalismo e legalismo? Sendo a efetividade da tutela jurisdicional complementar à segurança jurídica, harmonizá-los nas conciliações é possível? Na verdade, a eficiência não pode ser furto de decisões rápidas e baratas, mas por meio de um modelo processual que permita conciliar com rapidez, economia e qualidade, ou seja, com justiça e pacificação social.

O estudo permite fazer uma reflexão sobre a conciliação nos moldes do novo CPC que, apesar de ter apostado acertadamente no meio consensual, pode esbarrar na dificuldade de concretizar tal instituto na prática. Em resumo, a teoria é perfeita, mas a prática pode ser um problema. Além dos aspectos previstos no próprio códex como impedimento à concreção, outros fatores, alheios ao controle do judiciário, como a cultura demandista, a dependência do povo ao judiciário, a busca equivocada por justiça, ainda prevalecem. Mas, é válida a aposta do novo código nos meios consensuais, pois, além de buscar sanar a crise promovendo um processo justo e constitucionalizado, pretende alcançar a pacificação social, contribuindo com as relações pessoais.

\section{Conclusão}

A industrialização de processos formada pelo enraizamento de uma cultura demandista faz com que o jurisdicionado acredite que o acesso à justiça se dê apenas através de uma sentença, prejudicando o poder judiciário e, por sequência, a paz social. É permitido compreender que a solução dos problemas do sistema processual através da lei é uma utopia, porque aspectos culturais e sociais estão envolvidos nessa problemática, demandando não só a aplicação da legislação, mas a participação, conscientização e responsabilidade dos envolvidos na solução do conflito (GAJARDONI, 2015).

Esta análise crítica-reflexiva se propôs a questionar o instituto da conciliação, como meio consensual destinado a amenizar a crise judiciária, ao passo que promove a pacificação social. Tratou de averiguar se a previsão do instituto se preocupa em sanar demandas ou trabalhar a solução do conflito, considerando as peculiaridades e necessidades das partes.

É possível concluir que o texto legal acertou em apostar nos meios consensuais, no entanto se deslumbra ao colocar o instituto como o único caminho para tanto. Isso porque constranger o jurisdicionado a se autocompor contradiz o próprio código e seus aspectos principiológicos. Conciliar requer voluntariedade, ao passo que 
forçar alguém a tentar é negar acesso à justiça. Manter a audiência mesmo contra a vontade de uma das partes é ir à contramão dos preceitos estabelecidos e suscitados como fundamentais para o exercício da democracia e da cidadania, em busca de um processo justo e de resultados satisfatórios, impedindo a promoção da segurança jurídica e da efetividade.

O Código de Processo Civil coloca em risco os objetos que ele mesmo disciplinou, pois há uma linha tênue entre os princípios constitucionais acima elencados. A noção de cooperação processual pode ser deturpada perante a obrigatoriedade da audiência inicial de conciliação. Em determinado momento, o princípio da cooperação será confrontando pela cultura demandista do País.

A obrigatoriedade não é um problema isolado para a concreção da conciliação. O próprio instituto pode ser usado como manobra protelatória para atrasar o processo e o Magistrado em nada poderá interferir, tornando ainda mais moroso o procedimento, ferindo, inclusive, o princípio da celeridade processual. A implementação (imposição) da conciliação e a ênfase à autonomia privada consistem em institutos contraditórios no novo CPC e impedem a concretude da conciliação na prática. As audiências de conciliação são instaladas, mas não são conduzidas de forma a trabalhar as peculiaridades e necessidades das partes, visando à solução do conflito de forma primordial.

A análise crítica-reflexiva proposta conclui que a conciliação no novo CPC não é utilizada com o propósito do legislador, porque inicialmente é preciso repensar as estruturas jurídicas para dirimir a crise, ao passo que promove maior eficácia do que a solução imposta por uma sentença. Isto é, o ponto crucial para que a eficácia seja alcançada é que na conciliação resulte um acordo que dê segurança jurídica, resultados satisfatórios e em tempo hábil, ou seja, que seja melhor do que a decisão imposta pela sentença preferida por um terceiro. Neste momento, será possível contribuir para a mudança cultural, melhorando a relação das pessoas na sociedade, fomentando a justiça coexistencial e promovendo a pacificação social.

\section{Referências}

BENEDITO, L. M. F. B.; GAMBOGI, L. C. B. $O$ novo diploma processual civil e a cultura da cooperação através do convite conciliatório. 2017. Disponível em: <http://www.conpedi.org.
br/publicacoes/02q8agmu/6p264t76/9YIa5nV75 3zOru20.pdf>. Acesso em: 5 abr. 2017.

BRASIL. Constituição da República Federativa do Brasil de 1988. Brasília: Senado Federal, 1988.

BRASIL. Resolução no 125 de 29 de Novembro de 2010. Dispõe sobre a Política Judiciária Nacional de tratamento adequado dos conflitos de interesses no âmbito do Poder Judiciário e dá outras providências. Diário Oficial [da] República Federativa do Brasil, Brasília, 2010.

CAMBI, E.; BUENO, F. B. S. Segurança jurídica e efetividade processual. Revista dos Tribunais Sul, v. 5, p. 175-190, 2014.

DEMARCHI, J. Mediação: proposta de implementação no processo civil brasileiro. 2007. 308 f. Tese (Doutorado) - Faculdade de Direito, Universidade de São Paulo, 2007. Disponível em: $<$ http://www.teses.usp.br/teses/disponiveis/2/2137/ tde-01042008-132345/pt-br.php>. Acesso em: 20 maio 2017.

GAJARDONI, F. F. Novo CPC: vale apostar na conciliação/mediação? 2015. Disponível em: < http://jota.info/novo-cpc-vale-apostar-naconciliacaomediacao $>$. Acesso em: 28 jun. 2015.

MELO, G. M. O acesso adequado à justiça na perspectiva do justo processo. 2015. Disponível em: $<$ http://www.ibds.com.br/artigos/OACESSOADE QUADOaJUSTICANAPERSPECTIVADOJUSTO PROCESSO.pdf $>$. Acesso em: 19 abr. 2017.

MENDES, M. L. R. C. P. Mediação e conciliação histórico dos métodos adequados de solução de conflitos e experiências contemporâneas no Brasil e em outros países: das técnicas de mediação, suas nuances, pontos convergentes e aspectos práticos. In: TOLEDO, A. S. P.; TOSTA, J.; ALVES, J. C. F. (Coord.). Estudos avançados de mediação e arbitragem. Rio de Janeiro: Elsevier, 2014.

NUNES JUNIOR, A. T. As modernas teorias da justiça. 2015. Disponível em: <http://www2. senado.leg.br/bdsf/bitstream/handle/id/815/R15606.pdf? sequence $=4>$. Acesso em 23 maio 2015.

SANTOS, B. S. Pela mão de Alice: o social e o político na pós-modernidade. 7. ed. São Paulo: Cortez, 1999, p. 167.

SILVA, A. C. V. As práticas de mediação e conciliação como instrumentos de promoção da 
cidadania: uma releitura sob a ótica da democracia participativa. 2014. 114 f. Dissertação (Mestrado em Direitos Coletivos e Cidadania) - Faculdade de Direito "Laudo de Camargo", Universidade de Ribeirão Preto, Ribeirão Preto, 2014.
STUMPF, J. C. Poder judiciário: morosidade e inovação. 2008. 175 f. Dissertação (Mestrado Profissionalizante em Poder Judiciário) - Escola de Direito do Rio de Janeiro, Fundação Getulio Vargas, Rio de Janeiro, 2008. 